\title{
Mild behavioral impairment: measurement and clinical correlates of a novel marker of preclinical Alzheimer's disease
}

\author{
Byron Creese $^{1 *}$ (1) and Zahinoor Ismail ${ }^{2}$
}

\begin{abstract}
Background: Late-life onset neuropsychiatric symptoms are established risk factors for dementia. The mild behavioral impairment (MBI) diagnostic framework was designed to standardize assessment to determine dementia risk better. In this Mini Review, we summarize the emerging clinical and biomarker evidence, which suggests that for some, $\mathrm{MBI}$ is a marker of preclinical Alzheimer's disease.

Main: $\mathrm{MBl}$ is generally more common in those with greater cognitive impairment. In community and clinical samples, frequency is around 10-15\%. Mounting evidence in cognitively normal samples links MBI symptoms with known AD biomarkers for amyloid, tau, and neurodegeneration, as well as AD risk genes. Clinical studies have found detectable differences in cognition associated with MBI in cognitively unimpaired people.

Conclusion: The emerging evidence from biomarker and clinical studies suggests $\mathrm{MBI}$ can be an early manifestation of underlying neurodegenerative disease. Future research must now further validate MBI to improve identification of those at the very earliest stages of disease.
\end{abstract}

Keywords: Mild behavioral impairment, Neuropsychiatric symptoms, Preclinical AD, Cognition, Biomarkers

\section{Background}

There exists an urgent need to improve early detection of Alzheimer's disease (AD) in order to optimize interventions in preclinical phases and potentially improve the success rates of trials of disease-modifying therapies. Access to biomarkers for preclinical disease detection is improving, but screening of cognitively asymptomatic populations remains inefficient and costly. Therefore, attention has turned to enrichment strategies to identify those most likely to screen positive; these should be lowcost, quick, and easy to administer at large. Screening on late-life onset neuropsychiatric symptoms (NPS) may represent such a strategy.

*Correspondence: b.creese@exeter.ac.uk

${ }^{1}$ Medical School, College of Medicine and Health, University of Exeter, Exeter, UK

Full list of author information is available at the end of the article
Later-life NPS are reliably associated with a greater risk of mild cognitive impairment (MCI) and dementia [1-8]. This evidence motivated the development of the mild behavioral impairment (MBI) diagnostic framework, which operationalizes and standardizes the assessment of NPS in older adults, to improve risk determination of all-cause dementia. It is well appreciated that emergent behavioral symptoms can presage frontotemporal dementia. However, the behavioral prodrome is less appreciated in $\mathrm{AD}$, and thus, $\mathrm{AD}$ is the focus of this review. Here, we introduce MBI and its measurement and review major clinical and biomarker research, which suggests that MBI can represent an early manifestation of AD.

\section{Main}

MBI is a later-life onset neurobehavioral syndrome that may emerge at any point along the pre-dementia original author(s) and the source, provide a link to the Creative Commons licence, and indicate if changes were made. The images or other third party material in this article are included in the article's Creative Commons licence, unless indicated otherwise in a credit line to the material. If material is not included in the article's Creative Commons licence and your intended use is not permitted by statutory regulation or exceeds the permitted use, you will need to obtain permission directly from the copyright holder. To view a copy of this licence, visit http://creativecommons.org/licenses/by/4.0/. The Creative Commons Public Domain Dedication waiver (http://creativeco mmons.org/publicdomain/zero/1.0/) applies to the data made available in this article, unless otherwise stated in a credit line to the data. 
spectrum, from normal cognition to subjective cognitive decline (SCD) through to MCI. MBI represents a neurobehavioral axis, alongside the traditional neurocognitive axis, of pre-dementia symptoms. MBI is not a competing construct to $\mathrm{MCI}$, but rather, a complementary behavioral analog. Just as emergent cognitive symptoms in late life can reflect neurodegeneration, so can emergent behaviors. These behaviors in MBI are clustered into five domains (Table 1).

In 2016, an Alzheimer's Association working group published diagnostic criteria for MBI (Table 1), and the Mild Behavioral Impairment Checklist (MBI-C) was developed to capture the full symptom spectrum in accordance with the criteria $[9,10]$. The MBI-C is free, has been validated in clinical and community samples, and can be administered in person, by telephone, or unsupervised online [11-16]. Two primary questions relating to assessment using the MBI-C remain outstanding, specifically the cut points for case ascertainment, and the use of self- versus informant-reports. Regarding MBI-C cut points, 6.5 and 8.5 in MCI and SCD samples show good sensitivity and specificity for gold-standard clinical diagnosis of MBI $[12,13]$. However, there is no similar research for individual MBI domains. Most studies use informant-reports but self-reported MBI is also associated with worse cognition, highlighting its potential importance [17]. Although symptoms are reported at a similar frequency when comparing self- and informantreports, the two are only weakly correlated, and therefore possibly capture different groups [11]. The role of anosognosia has not been explored fully in MBI, an understanding of which may provide further insights into the sources of information, and help direct the appropriate use self- or informant-reports [18].

Prevalence estimates of MBI vary considerably according to the instrument used and the sample studied. Generally, MBI is more prevalent with greater cognitive impairment. Studies using the Neuropsychiatric Inventory (NPI, developed for established dementia), place prevalence as high as $49-85 \%$ in MCI and $28-75 \%$ in pre-MCI samples $[19,20]$. Studies using the MBI-C yield more conservative estimates of $14 \%$ in $\mathrm{MCI}$ and $6-9 \%$ in pre-MCI $[12,13,16,17]$. These estimates are more accurate due to MBI-C stipulations that symptoms emerge de novo in later life and persist for at least 6 months. These requirements result in better specificity for symptoms representing the manifestations of neurodegenerative disease, with transient symptoms and those representing life stressors less likely to be included [21]. Studies using the MBI-C in memory clinics report prevalence of $28-37 \%$ in SCD and $47-54 \%$ in MCI $[15,22]$, emphasizing the clinical significance of behavioral symptoms [23]. Impulse dyscontrol and affective dysregulation have been reliably identified as the two most common individual MBI domains by multiple independent studies [11, 13, $19,20,22,24-26]$.

Longitudinal and cross-sectional studies have consistently linked MBI with poorer cognition and progression to MCI and dementia [16, 17, 21, 25, 27-30]. Studies of detailed neuropsychology in cognitively normal $(\mathrm{CN})$ individuals have shown differences in executive function, attention, working memory, and episodic memory associated with MBI across a number of independent studies $[16,17,25,30]$. Interestingly, one study has shown MBI with MCI to confer a greater degree of episodic

Table 1 ISTAART research diagnostic criteria for Mild Behavioral Impairment

\footnotetext{
1. Changes in behavior or personality observed by patient, informant, or clinician, starting later in life (age $\geq 50$ years) and persisting at least intermittently for $\geq 6$ months. These represent a clear change from the person's usual behavior or personality as evidenced by at least one of the following: a. Decreased motivation (e.g., apathy, aspontaneity, indifference)

b. Affective dysregulation (e.g., anxiety, dysphoria, changeability, euphoria, irritability)

c. Impulse dyscontrol (e.g., agitation, disinhibition, gambling, obsessiveness, behavioral perseveration, stimulus bind)

d. Social inappropriateness (e.g., lack of empathy, loss of insight, loss of social graces or tact, rigidity, exaggeration of previous personality traits)

e. Abnormal perception or thought content (e.g., delusions, hallucinations)

2. Behaviors are of sufficient severity to produce at least minimal impairment in at least one of the following areas:

a. Interpersonal relationships

b. Other aspects of social functioning

c. Ability to perform in the workplace

The patient should generally maintain his/her independence of function in daily life, with minimal aids or assistance.

1. Although comorbid conditions may be present, the behavioral or personality changes are not attributable to another current psychiatric disorder (e.g., generalized anxiety disorder, major depression, manic or psychotic disorders), traumatic or general medical causes, or the physiological effects of a substance or medication.

2. The patient does not meet criteria for a dementia syndrome (e.g., Alzheimer's disease, frontotemporal dementia, dementia with Lewy bodies, vascular dementia, other dementia). $\mathrm{MCl}$ can be concurrently diagnosed with $\mathrm{MBI}$.
} 
memory impairment than MCI without MBI but it is not known to what extent these broad early cognitive deficits might indicate risk for specific types of neurodegenerative disease [25]. Effect sizes in these studies were smallto-medium but the findings are important and suggest detectable differences in cognition exist. Longitudinal studies are required to determine whether MBI emerges in advance or after these subtle changes.

In a sample of over 4000 people stratified by MBI status, $\mathrm{AD}$ genetic risk was associated with cognitive performance in those with MBI but not in those without. These findings suggest screening on MBI may enrich samples for a cognitive phenotype associated with AD biomarkers [31]. While encouraging, no firm conclusions can be drawn about the etiology underlying genetic and cognitive associations. However, emerging biomarker evidence provides more concrete links with AD neuropathology.

A nascent literature operationalizing MBI using the NPI has linked symptoms with plasma neurofilament light, suggesting accelerated neurodegeneration, and has also shown a modest association with plasma $A \beta_{42} / A \beta_{40}$ $[32,33]$. There is also early evidence that impulse dyscontrol is associated with atrophy in the entorhinal cortex [34], a finding also reported in a different sample focused on a small number of brain regions selected a priori [35]. Greater medial temporal lobe atrophy was also associated with total MBI-C score in a subsequent study; however, these findings should be considered exploratory as only uncorrected $p$-values were presented in the small sample of 34 participants [36]. Amyloid PET is a gold standard biomarker of $\mathrm{AD}$ and in a recent landmark study of $\mathrm{CN}$ older adults, MBI score was correlated with both global and striatal $\mathrm{A} \beta$ burden [24]. Moreover, of the 7 participants scoring above 8 on the MBI-C, 5 (71\%) were amyloid positive, compared with $25 \%$ of those scoring $<8$ [24]. There was no association with tau PET in this sample. A separate study of $A \beta$ positive $C N$ participants (i.e., preclinical $\mathrm{AD}$ ), found higher $\mathrm{MBI}-\mathrm{C}$ scores were associated with tau PET uptake in the entorhinal cortex and hippocampus, as well as higher CSF p-tau ${ }_{181}$ [37]. Reconciling these seemingly contradictory studies requires an appreciation of the difference in amyloid positivity. Given that amyloid is likely required for abnormal tau, the sampling difference with respect to amyloid positivity in the two studies may explain the discrepancy. Collectively, then, evidence from MRI and PET implicates medial temporal lobe structures. Interestingly, tau PET was not associated with delayed recall in the preclinical AD study, suggesting the MBI association did not simply reflect memory deficits. One explanation for the association is the "agitation network" proposed by Rosenberg et al. that comprises medial temporal lobe structures (including the hippocampus and amygdala) and frontal and anterior cingulate cortices [38]. Alternatively, given that the sample had preclinical $\mathrm{AD}$, and not prodromal $\mathrm{AD} / \mathrm{MCI}$, by definition cognition should be normal, with the behavioral changes representing sequelae of amyloid and/or tau. Further studies are needed to explore these findings.

These initial biomarker findings are exciting, but it is important to highlight that the literature remains in its infancy. Specifically, small sample sizes and only a small number of independent studies remain a limitation. Functional imaging studies are also needed to elucidate specific brain networks correlated with MBI symptoms. Notwithstanding these limitations, the literature is promising, and these data provide a clear rationale for empirical validation of MBI as a sample enrichment strategy in longitudinal studies using established and novel biomarkers $[39,40]$. Furthermore, the exploration of associations with non-AD biomarkers is essential given that depending on the nature of the clinical sample, some studies have shown a substantial proportion of patients with MBI can progress to Lewy body and frontotemporal dementia as well $[29,30,41]$.

\section{Conclusions}

An urgent need exists for a clinical marker to help identify people in the early stages of $\mathrm{AD}$, alongside biomarker screening. MBI criteria provide a standardized approach to NPS assessment and meet the basic requirements of an enrichment strategy; assessment is quick, cheap, and scalable to large samples. Research is needed to optimize measurement, focus on individual MBI domains, and reconcile self- and informant-reports. Nonetheless, mounting evidence suggests that MBI is associated with cognitive decline and a variety of $\mathrm{AD}$ biomarkers in cognitively normal samples, positioning it as a novel marker of preclinical disease. Future research must now understand MBI associations with accumulating AD pathology to validate it as a prognostic enrichment strategy.

\section{Abbreviations \\ AD: Alzheimer's disease; Aß: Amyloid beta; CSF : Cerebrospinal fluid; MBI : Mild behavioral impairment; MBI-C: Mild Behavioral Impairment Checklist; MCI: Mild cognitive ilmpairment; NPS: Neuropsychiatric symptoms; PET: Positron emission tomography; SCD : Subjective cognitive decline.}

\section{Acknowledgements}

Not applicable.

\section{Authors' contributions}

$\mathrm{BC}$ and ZI: conception, manuscript drafting, manuscript revision. Both authors contributed equally and have read and approved the final manuscript.

\section{Funding}

Zl is funded by the Canadian Institutes of Health Research (BCA399583).

Availability of data and materials

Not applicable. 


\section{Declarations}

Ethics approval and consent to participate

Not applicable.

\section{Consent for publication}

Not applicable.

\section{Competing interests}

$\mathrm{BC}$ declares that they have no competing interests.

ZI has received honoraria/consulting fees from Lundbeck and Otsuka outside the submitted work. His institution has received funds from Acadia, Biogen, Roche, and Sunovion.

\section{Author details}

${ }^{1}$ Medical School, College of Medicine and Health, University of Exeter, Exeter, UK. ${ }^{2}$ Departments of Psychiatry, Clinical Neurosciences, Community Health Sciences, and Pathology, Hotchkiss Brain Institute, University of Calgary, Calgary, Alberta, Canada.

Received: 2 July 2021 Accepted: 14 December 2021

Published online: 05 January 2022

\section{References}

1. Masters MC, Morris JC, Roe CM. "Noncognitive" symptoms of early Alzheimer disease: a longitudinal analysis. Neurology. 2015;84:617-22.

2. Kohler S, Allardyce J, Verhey FR, McKeith IG, Matthews F, Brayne C, et al. Cognitive decline and dementia risk in older adults with psychotic symptoms: a prospective cohort study. Am J Geriatr Psychiatry. 2013:21:119-28.

3. Donovan NJ, Amariglio RE, Zoller AS, Rudel RK, Gomez-Isla T, Blacker D, et al. Subjective cognitive concerns and neuropsychiatric predictors of progression to the early clinical stages of Alzheimer disease. Am J Geriatr Psychiatry. 2014;22:1642-51.

4. Banks SJ, Raman R, He F, Salmon DP, Ferris S, Aisen P, et al. The Alzheimer's disease cooperative study prevention instrument project: longitudinal outcome of behavioral measures as predictors of cognitive decline. Dement Geriatr Cogn Dis Extra. 2014;4:509-16.

5. Geda YE, Roberts RO, Mielke MM, Knopman DS, Christianson TJH, Pankratz VS, et al. Baseline neuropsychiatric symptoms and the risk of incident mild cognitive impairment: a population-based study. Am J Psychiatry. 2014;171:572-81. Available from. https://doi.org/10.1176/appi.ajp.2014. 13060821.

6. Wise EA, Rosenberg PB, Lyketsos CG, Leoutsakos J-M. Time course of neuropsychiatric symptoms and cognitive diagnosis in National Alzheimer's Coordinating Centers volunteers. Alzheimer's Dement (Amsterdam, Netherlands). 2019;11:333-9.

7. Korner A, Lopez AG, Lauritzen L, Andersen PK, Kessing LV. Acute and transient psychosis in old age and the subsequent risk of dementia: a nationwide register-based study. Geriatr Gerontol Int. 2009;9:62-8.

8. Mallo SC, Valladares-Rodriguez S, Facal D, Lojo-Seoane C, FernándezIglesias MJ, Pereiro AX. Neuropsychiatric symptoms as predictors of conversion from $\mathrm{MCl}$ to dementia: a machine learning approach. Int Psychogeriatrics. 2020;32:381-92.

9. Ismail Z, Smith EE, Geda Y, Sultzer D, Brodaty H, Smith G, et al. Neuropsychiatric symptoms as early manifestations of emergent dementia: provisional diagnostic criteria for mild behavioral impairment. Alzheimers Dement. 2016;12:195-202.

10. Ismail Z, Agüera-Ortiz L, Brodaty H, Cieslak A, Cummings J, Fischer CE, et al. The mild behavioral impairment checklist (MBI-C): a rating scale for neuropsychiatric symptoms in pre-dementia populations. J Alzheimers Dis. 2017;56:929-38 Available from: http://www.ncbi.nlm.nih.gov/pmc/ articles/PMC5652315/.

11. Creese B, Griffiths A, Brooker H, Corbett A, Aarsland D, Ballard C, et al. Profile of mild behavioral impairment and factor structure of the mild behavioral impairment checklist in cognitively normal older adults. Int Psychogeriatr. 2019;32:705-17.
12. Mallo SC, Ismail Z, Pereiro AX, Facal D, Lojo-Seoane C, Campos-Magdaleno $M$, et al. Assessing mild behavioral impairment with the mild behavioral impairment checklist in people with subjective cognitive decline. Int Psychogeriatr. 2018;31:231-9.

13. Mallo SC, Ismail Z, Pereiro AX, Facal D, Lojo-Seoane C, Campos-Magdaleno $M$, et al. Assessing mild behavioral impairment with the mild behavioral impairment-checklist in people with mild cognitive impairment. J Alzheimers Dis. 2018;66:83-95.

14. Cui Y, Dai S, Miao Z, Zhong Y, Liu Y, Liu L, et al. Reliability and validity of the Chinese version of the mild behavioral impairment checklist for screening for Alzheimer's disease. J Alzheimers Dis. 2019;70:747-56.

15. Hu S. Validation of the mild behavioral impairment-checklist in subjective cognitive decline, mild cognitive impairment and dementia. 2019. Available from: http://hdl.handle.net/1880/110515

16. Kassam F, Chen H-Y, Nosheny RL, Williams T, Mackin RS, Weiner MW, et al. Cognitive profile of mild behavioral impairment (MBI) in brain health registry participants. Alzheimers Dement. 2020;16:e047673.

17. Creese B, Brooker H, Ismail Z, Wesnes KA, Hampshire A, Khan Z, et al. Mild behavioral impairment as a marker of cognitive decline in cognitively Normal older adults. Am J Geriatr Psychiatry. 2019;27:823-34.

18. Brunet HE, Cummings JL, Banks SJ, Miller JB. Awareness of psychiatric symptoms in a mixed clinical sample of older adults. J Geriatr Psychiatry Neurol. 2019;33:124-34. Available from. https://doi.org/10.1177/08919 88719868311.

19. Sheikh F, Ismail Z, Mortby ME, Barber P, Cieslak A, Fischer K, et al. Prevalence of mild behavioral impairment in mild cognitive impairment and subjective cognitive decline, and its association with caregiver burden. Int Psychogeriatr. 2018;30:233-44.

20. Mortby ME, Ismail Z, Anstey KJ. Prevalence estimates of mild behavioral impairment in a population-based sample of pre-dementia states and cognitively healthy older adults. Int Psychogeriatr. 2018:30:221-32.

21. Ismail Z, McGirr A, Gill S, Hu S, Forkert ND, Smith EE. Mild behavioral impairment and subjective cognitive decline predict cognitive and functional decline. J Alzheimers Dis. 2021;80:459-69.

22. Rao A, Thakral M, Saini M, Chatterjee P, Dey A. Blood biomarkers in older subjects with mild behavioral impairment: a cross-sectional study from the memory clinic, all India institute of medical sciences. India J Indian Acad Geriatr. 2020;16:91-4 Available from: http://www.jiag.com/article. asp?issn $=0974-3405$.

23. Ismail Z, Elbayoumi H, Fischer CE, Hogan DB, Millikin CP, Schweizer T, et al. Prevalence of depression in patients with mild cognitive impairment: a systematic review and meta-analysis. JAMA Psychiatry. 2017;74:58-67. Available from. https://doi.org/10.1001/jamapsychiatry.2016.3162.

24. Lussier FZ, Pascoal TA, Chamoun M, Therriault J, Tissot C, Savard M, et al. Mild behavioral impairment is associated with $\beta$-amyloid but not tau or neurodegeneration in cognitively intact elderly individuals. Alzheimer's Dement. 2020;16:192-9 Available from: https://alz-journals.onlinelibrary. wiley.com/doi/abs/10.1002/alz.12007.

25. Rouse HJ, Small BJ, Schinka JA, Loewenstein DA, Duara R, Potter H. Mild behavioral impairment as a predictor of cognitive functioning in older adults. Int Psychogeriatr. 2021;33:285-93.

26. Fan S, Liang X, Yun T, Pei Z, Hu B, Ismail Z, et al. Mild behavioral impairment is related to frailty in non-dementia older adults: a cross-sectional study. BMC Geriatr. 2020;20:510. Available from. https://doi.org/10.1186/ s12877-020-01903-2.

27. Matsuoka T, Ismail Z, Narumoto J. Prevalence of mild behavioral impairment and risk of dementia in a psychiatric outpatient clinic. J Alzheimers Dis. 2019;70:505-13.

28. Tsunoda K, Yamashita T, Osakada Y, Sasaki R, Tadokoro K, Matsumoto $\mathrm{N}$, et al. Positive baseline behavioral and psychological symptoms of dementia predict a subsequent cognitive impairment in cognitively normal population. Neurol Clin Neurosci. 2021;9:218-22. Available from. https://doi.org/10.1111/ncn3.12492.

29. Taragano FE, Allegri RF, Heisecke SL, Martelli MI, Feldman ML, Sanchez $V$, et al. Risk of conversion to dementia in a mild behavioral impairment group compared to a psychiatric group and to a mild cognitive impairment group. J Alzheimers Dis. 2018;62:227-38.

30. Taragano FE, Allegri RF, Krupitzki H, Sarasola DR, Serrano CM, Loñ L, et al. Mild behavioral impairment and risk of dementia: a prospective cohort study of 358 patients. J Clin Psychiatry. 2009;70:584-92 Available from: https://pubmed.ncbi.nlm.nih.gov/19323967. 
31. Creese B, Arathimos R, Brooker H, Aarsland D, Corbett A, Lewis C, et al. Genetic risk for Alzheimer's disease, cognition, and mild behavioral impairment in healthy older adults. Alzheimer's Dement Diagnosis Assess Dis Monit. 2021;13:e12164. Available from. https://doi.org/10.1002/dad2. 12164.

32. Naude JP, Gill S, Hu S, McGirr A, Forkert ND, Monchi O, et al. Plasma Neurofilament light: a marker of neurodegeneration in mild behavioral impairment. J Alzheimers Dis. 2020;76:1017-27.

33. Miao R, Chen H-Y, Gill S, Naude J, Smith EE, Ismail Z. Plasma $\beta$-amyloid in mild behavioural impairment - neuropsychiatric symptoms on the Alzheimer's continuum. J Geriatr Psychiatry Neurol.

34. Gill S, Wang M, Mouches P, Rajashekar D, Sajobi T, MacMaster FP, et al. Neural correlates of the impulse dyscontrol domain of mild behavioral impairment. Int J Geriatr Psychiatry. 2021;n/a. Available from. https://doi. org/10.1002/gps.5540.

35. Matuskova V, Ismail Z, Nikolai T, Markova H, Cechova K, Nedelska Z, et al. Mild behavioral impairment is associated with atrophy of entorhinal cortex and hippocampus in a memory clinic cohort. Front Aging Neurosci. 2021;13:643271 Available from: https://pubmed.ncbi.nlm.nih.gov/34108 874.

36. Shu J, Qiang Q, Yan Y, Wen Y, Ren Y, Wei W, et al. Distinct patterns of brain atrophy associated with mild behavioral impairment in cognitively normal elderly adults. Int J Med Sci. 2021;18:2950-6 Available from: https:// www.medsci.org/v18p2950.htm.

37. Johansson M, Smith R, Stomrud E, Johansson P, Janelidze S, van Westen $D$, et al. Mild behavioral impairment is predictive of tau deposition in the earliest stages of Alzheimer's disease. Alzheimer's Dement. 2020;16:e042595. Available from. https://doi.org/10.1002/alz.042595.

38. Rosenberg PB, Nowrangi MA, Lyketsos CG. Neuropsychiatric symptoms in Alzheimer's disease: what might be associated brain circuits? Mol Asp Med. 2015;43-44:25-37.

39. Karikari TK, Pascoal TA, Ashton NJ, Janelidze S, Benedet AL, Rodriguez $J$, et al. Blood phosphorylated tau 181 as a biomarker for Alzheimer's disease: a diagnostic performance and prediction modelling study using data from four prospective cohorts. Lancet Neurol. 2020;19:422-33.

40. Ashton NJ, Pascoal TA, Karikari TK, Benedet AL, Lantero-Rodriguez J, Brinkmalm G, et al. Plasma p-tau231: a new biomarker for incipient Alzheimer's disease pathology. Acta Neuropathol. 2021;141:709-24.

41. Orso B, Mattei C, Arnaldi D, Massa F, Serafini G, Plantone D, et al. Clinical and MRI predictors of conversion from mild Behavioural impairment to dementia. Am J Geriatr Psychiatry. 2020;28:755-63 Available from: https:// www.sciencedirect.com/science/article/pii/S106474811930586X.

\section{Publisher's Note}

Springer Nature remains neutral with regard to jurisdictional claims in published maps and institutional affiliations.

Ready to submit your research? Choose BMC and benefit from:

- fast, convenient online submission

- thorough peer review by experienced researchers in your field

- rapid publication on acceptance

- support for research data, including large and complex data types

- gold Open Access which fosters wider collaboration and increased citations

- maximum visibility for your research: over 100M website views per year

At BMC, research is always in progress.

Learn more biomedcentral.com/submissions 